\title{
Multi-temporal analysis of vegetation reflectance using MERIS data in the Czech Republic
}

\section{Abstract}

Accurate high temporal resolution data is a very important source of information for understanding processes in the landscape. High temporal and spectral resolution data enable the monitoring of dynamic landscape processes. For this reason, since 2008 a receiving station for Metosat, NOAA and Envisat data has been installed at the Department of Applied Geoinformatics and Cartography, Faculty of Science, Charles University in Prague. The aim of this study is to analyse the spectral characteristics of vegetation using MERIS data in the Czech Republic. Spectral characteristics of vegetation were examined both by analysing changes in reflectivity as well as by utilising vegetation indices. Vegetation in forests and agricultural land was evaluated. The results present the spectral characteristics of selected associations of vegetation based on MERIS data and a discussion of the methods of multitemporal classification of land cover.

\section{Keywords}

High temporal data $\bullet$ MERIS $•$ Czech Republic $\bullet$ land cover $\bullet$ classification

() University of Warsaw - Faculty of Geography and Regional Studies
Přemysı Štych'1, Lucie Malíková2, Jan Kříż ${ }^{3}$, Lukáš Holman ${ }^{4}$

'Department of Applied Geoinformatics and Cartography Faculty of Science

Charles University in Prague

e-mail: stych@natur.cuni.cz

${ }^{2}$ Department of Applied Geoinformatics and Cartography Faculty of Science

Charles University in Prague

e-mail: lucie.malikova@natur.cuni.cz

${ }^{3}$ Department of Applied Geoinformatics and Cartography

Faculty of Science

Charles University in Prague

e-mail: jan.kriz@natur.cuni.cz

${ }^{4}$ Department of Applied Geoinformatics and Cartography

Faculty of Science

Charles University in Prague

e-mail: lukas.holman@natur.cuni.cz

Received: 11 October 2013

Accepted: 14 March 2014
Introduction

Land cover analysis has been one of the key research areas of environmental studies since the beginning of the satellite remote sensing epoch, providing in particular valuable information on the detection, location, condition and development of vegetation. In this regard, multitemporal satellite imageries are able to provide accurate and up to date maps of individual components of the vegetation cover. Numerous studies have examined the potential of multitemporal data with medium spatial resolution to identify different vegetation types primarily in the agricultural landscape.

Aurdal et al. (2005) used multitemporal data for land cover classification. Selected vegetation categories were distinguished on the basis of knowledge of phenological phases using Markov models. Junxiang et al. (2006) processed data from the AVHRR sensor using principal components analysis (PCA) and unsupervised classification (Isodata method). NDVI composites were created on the basis of measurements acquired over a 10-day period from data obtained over 7 months from February to August 2006 in the subtropical forests of Eastern Asia. Land cover classification was based on 6 categories and reached an accuracy of about $80 \%$.

At the beginning of the 21st century the MERIS sensor was an important source of high-temporal data. The ENVISAT mission where the MERIS sensor was installed took 10 years over the period 2002-2012. MERIS data has been used in many studies for the mapping of chlorophyll content and determining the characteristics of oceans or water bodies on the continents. The application of this data for terrestrial mapping was not so common, but studies on vegetation mapping using MERIS data were gradually carried over the subsequent years. For example, it is worth mentioning Zurita-Mill's (2008) study, which explored the possibilities of using MERIS data for the classification of heterogeneous elements of the landscape. Landsat (TM) and MERIS data were fused to obtain a high spatial resolution data source. Dash et al. (2005) and Zurita-Mill (2008) developed and used the vegetation indices MERIS Global Vegetation Index (MGVI) and MERIS Terrestrial Chlorophyll Index (MTCI) for MERIS images to achieve better classification results. These two indices were specially created for MERIS data and they provide useful information for the classification of individual vegetation classes using the 15 spectral bands of MERIS. For the purposes of land cover classification in the Czech Republic, MERIS data were applied by Brodsky et al. (2008). The classification, using the artificial neural network (ANN) model, was focused on five types of agricultural crops and gave results with a $68.1 \%$ accuracy of classification.

MERIS data was the main data source for the GlobCOVER and GlobCORINE projects. These projects are coordinated by ESA in cooperation with many other organizations such as FAO, UNEP, JRC, EEA, IGBP, UCL or GOFC-GOLD. Detailed information and the final land cover databases are available at European Space Agency 2010, GlobCover and European Space Agency 2010, GlobCorine. Even though the ENVISAT satellite lost contact in 2012 the results of studies based on MERIS and AATSR data provided valuable information. This will be used in the preparation and processing of data for the planned ESA Sentinel 2 mission and subsequently for Sentinel 3 , which will also have a multitemporal sensor on board. 


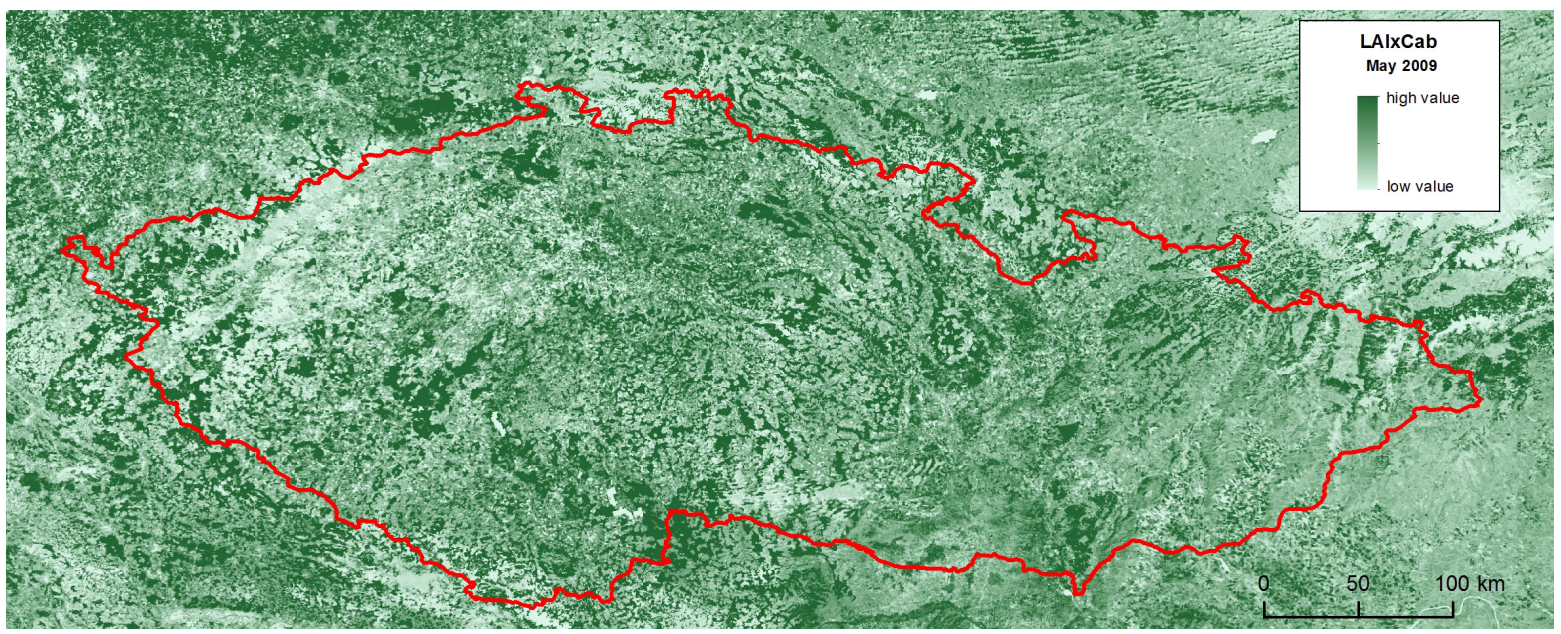

Figure 1. LAIxCab in the Czech Republic in May 2009

Source: Charles University in Prague - EO receiving station (2009)

\section{Data and methods}

MERIS images from April to September 2009 were the primary input data. Full Resolution (FR) MERIS data at the L1 level were used. The year 2009 was selected because of the availability of Land Parcel Information System (LPIS) reference data for this year. For the purposes of analysis, it was necessary to compile a selection of cloudless images. The software application EOLi was used for this purpose. EOLi (Earth Observation Link) is the European Space Agency's client for Earth observation catalogue and ordering services. Using EOLi allows the browsing of metadata and previewing of images of Earth observation data. For more information see: European Space Agency 2009, EOLI.

To compare the spectral characteristics of vegetation in several time periods, it was necessary to perform atmospheric, radiometric and geometric data correction. BEAM software was used to accomplish this task. BEAM is an open-source toolbox and development platform for the viewing, analysing and processing of remote sensing raster data. It was originally developed to facilitate the utilisation of image data from Envisat's optical instruments (European Space Agency 2010, BEAM). For the purpose of atmospheric correction in SW BEAM, it is necessary to determine the values of atmospheric aerosols - "Aerosol Optical Depth" (AOD) - for each specific day, set a regional character (continental, desert) and define a mask. AOD values were found at the GIOVANNI portal (Goddard Earth Sciences Data 2013). SMILE and SMAC radiometric corrections were then performed. The SMAC processor in BEAM transfers radiometric values (TOA Radiance) into surface reflectance (TOC reflectance). The next step was to carry out geometric correction. Orthorectification runs almost automatically in BEAM without the manual setting of input control points. GETASSE30 is BEAM's default elevation model. The data were transformed into WGS 84 coordinates. Nearest neighbour resampling was used during the process of orthorectification and the pixel size was defined as $300 \times 300 \mathrm{~m}$.

Calculating the LAlxCab index was the next important step. The LAIxCab index reflects the amount of chlorophyll in a plant. LAIxCab correlates with the amount of leaf area and chlorophyll $a$ and $b$ in plants (for more information see: Bacour et al. 2006). All calculations were performed using the MERIS Vegetation Processor in BEAM. The Vegetation Processor algorithm involves the neuron networks method, and 11 MERIS spectral bands (excluding the 1st, 2nd, 11th and 15th bands) plus additional data from the MERIS 1P product are used. The calculation of LAIxCab for the Czech Republic in May 2009 can be seen in Fig.1. From phenological phases of vegetation, the period of maturity can be determined using selected vegetation indices. See for example the studies of Dash et al. (2005) and Zurita-Mill (2008).

Masking methods were used to analyse changes in vegetation reflectance and vegetation index values. These masks were created in SW Beam in the "Mask / ROI Manager", on the basis of GlobCover reference data, LPIS and the results of field investigations. LPIS is a geographic information system that keeps records concerning the registration of agricultural land (LPIS Sitewell 2004). A forest mask was created using GlobCover and masks for agricultural land were created using LPIS data. GlobCover was used because this database was created based on MERIS data. The average reflectance and vegetation indices were calculated inside the masks using BEAM. The masks contain only valid pixels without cloud cover. Pixels with cloud cover were removed using the Probability Cloud tool. Changes in the spectral characteristics of coniferous, mixed and deciduous forests were examined under the forest mask, while oilseed rape, maize, sugar beets and hops were analysed under the mask of agricultural land. Data from the LPIS database and field surveys were used as the reference information for agricultural land. The observed vegetation types were found in the selected areas. In working with $300 \mathrm{~m}$ spatial resolution MERIS images, it is important that different vegetation categories are not allowed to mix with other categories. Therefore, the minimum size of an investigated area is 9 ha. In spite of the relatively accurate geolocation of the image (a maximum 1 pixel deflection), a pixel size of $3 \times 3$ was selected as the minimum unit for an investigated area. The central pixel was used as the reference pixel (endmember). MERIS and LPIS data were overlapped and the endmember pixels fell entirely into one block of land, so that the value of reflection involves only one type of crop. BEAM creates a spectral curve of vegetation types using two instruments - PIN and Spectrum Manager View. The spectral reflectance curve in BEAM can be exported into a *.csv file, which is a valid input for land cover classification, e.g. Linear Spectral Unmixing (LSU).

\section{Results}

The development of the spectral reflectance was evaluated over the year 2009. The average reflectance value was counted under the mask of the monitored vegetation surfaces. The average reflectance presented here was calculated for the landscape in the Czech Republic and represents general trends in vegetation components of the landscape. 


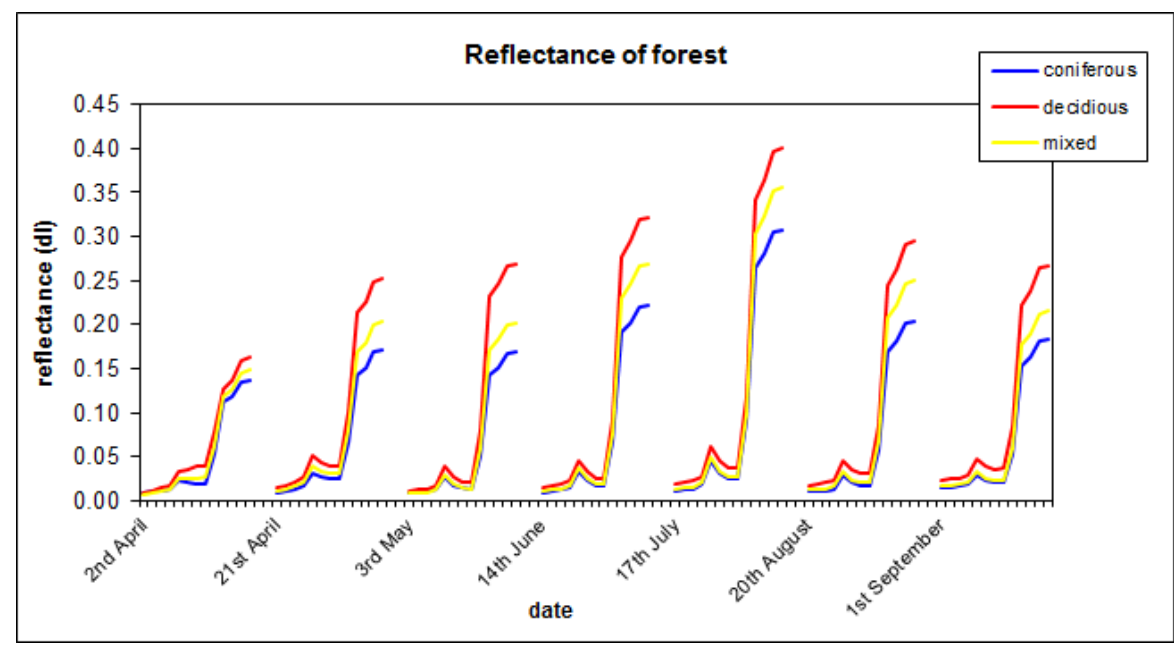

Figure 2. Reflectance of forest

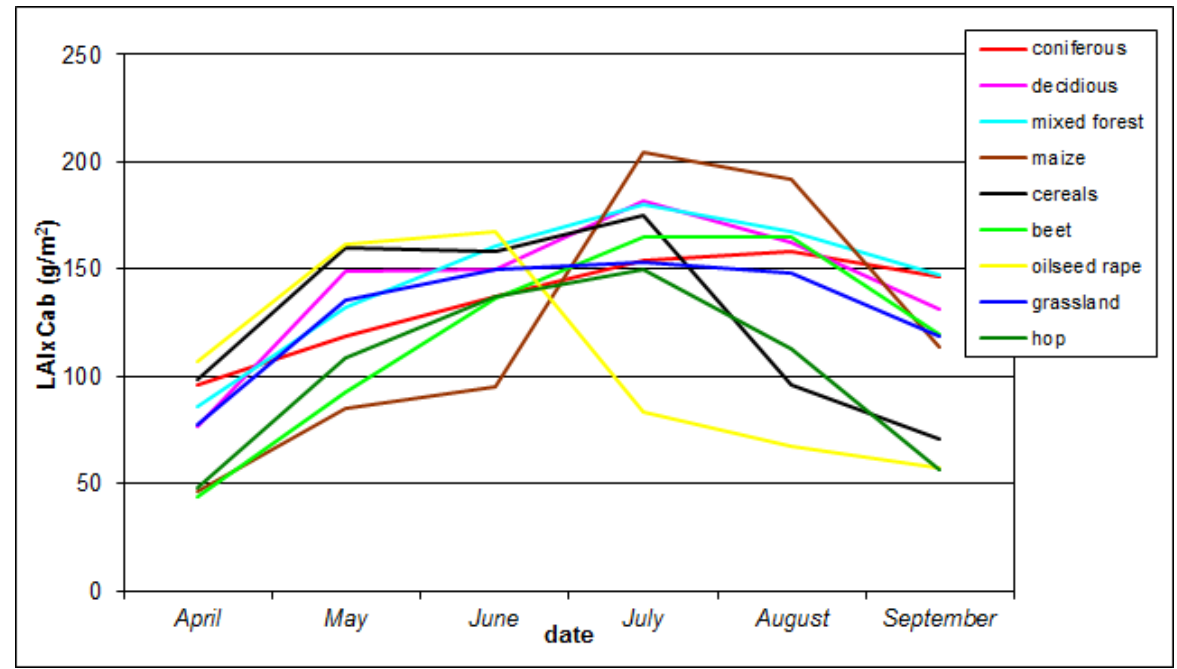

Figure 3. LAIXCab of vegetation

At the beginning of April, the different types of forest area demonstrated quite uniform reflectance (see Fig. 2). Differences in the spectral reflectance of coniferous and deciduous forests were evident only in the red part of the spectrum (band 7 and band 8), where the deciduous forests included bare soil in the reflectance. Deciduous forests during this period were not foliaged. By late April, the deciduous trees had more foliage. The reflectance in the near infrared area (band 10) increased and radiation in the red spectrum was absorbed by chlorophyll. The conifers reflected differently because of the specific morphological structure of their needles. This fact is confirmed by LAIxCab values, reflecting the amount of chlorophyll in a plant (see Fig. 3). Fig. 2 shows segments (break points) in the trend lines which correspond with the 15 bands of MERIS in blue, green, red and NIR spectral fields.

The development of agricultural plants (maize, cereals, beet, oilseed rape, permanent grassland and hops) during 2009 is presented in Fig. 4. In April, fields were predominantly covered by winter oilseed rape and winter cereals. The spectral reflectance curve reflected the characteristics of the vegetation - chlorophyll absorption in the $\mathrm{R}$ and higher reflectance in the NIR. Fields with spring and summer crops (maize and sugar beet) were absent of vegetation and therefore the spectral curve presented bare soil. Developments in the spectral reflectance of grassland did not show significant differences - there was only a slight increase in reflectance in the NIR during the summer months when vegetation is generally more vigorous. In July, the curves highlighted the reflectivity of vegetation in fields with corn and beets, while winter oilseed rape had already been reaped by this period. Reflectance in these areas was significantly influenced by bare soil. Fig. 3 confirms that the most suitable months for the classification of a broad range of land cover classes are July and August.

Developments in LAlxCab are shown in Fig. 3. From phenological phases of vegetation, the period of maturity can be determined using LAlxCab results. During its period of maturity a plant is visible in satellite images and its determination is significant. Oilseed rape was clearly the plant with the highest value of the examined index in April (Fig. 3). This crop reached its period of maturity in late May according to the LAlxCab indicator. Therefore, oilseed rape should be distinguishable and classifiable in May. Winter cereals reached similar LAlxCab values during April and May, but they had significantly lower reflectance at wavelengths from 0.7 to 0.9 i.e. in the near infrared. This spectral difference can be used to distinguish these two types of crops. Permanent grasslands were relatively 


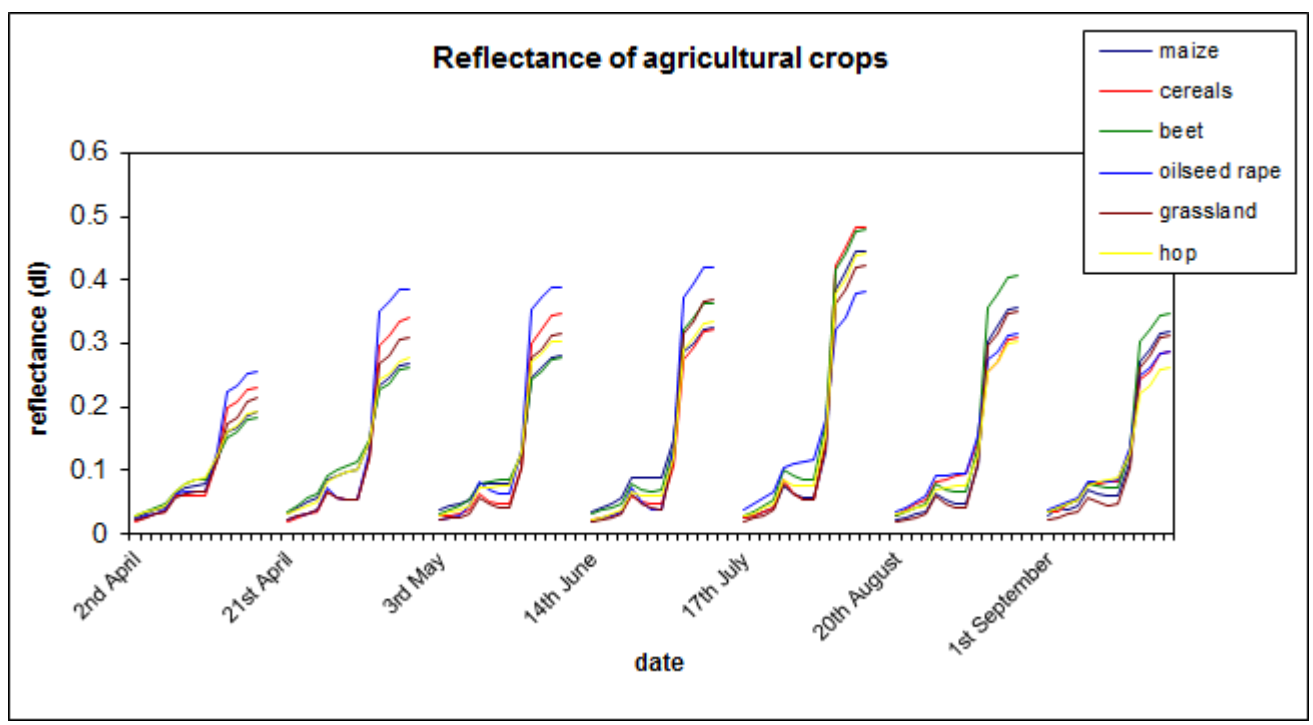

Figure 4. Reflectance of agricultural crops

stable in LAlxCab development, without significant maxima and minima. Sugar beets and hops also exhibited a continuous trend (gradual increase and gradual decrease) in phenological phases. The maturity period for hops was in July, for sugar beets in early August. Maize exhibited a unique phenological development. Huge increases in the LAlxCab of maize occurred during June and July and reached a maximum in late July and early August.

\section{Summary and discussion}

The study investigated the possibilities of using MERIS high temporal data for the detection of the spectral characteristics of vegetation. Approximately 15 high quality MERIS images, which contained a low percentage of cloud cover, were available for 2009. It was possible to combine all the images as a means of observing the development of spectral characteristics for each month. The different phenological phases of vegetation were identifiable. The LAlxCab vegetation index was used for this purpose. This index is particularly useful for determining the maturity of oilseed rape, maize and sugar beets and is an important source of data for multitemporal classification of land cover on agricultural land.

Data processing was carried out in BEAM, which offers complete data preprocessing, classification and calculation tools. The accuracy of atmospheric corrections plays a crucial role in the process of multitemporal analysis of the spectral reflectance of vegetation. This methodology, used for the SMAC atmospheric correction model implemented in BEAM, simply requires the entering of atmospheric aerosol values. This topic should receive detailed attention in further research. Proposals to calculate the characteristics of atmospheric and surface spectral reflectance data directly from MERIS have already been published by Guanter et al. (2007).

High temporal resolution data offer the possibility to map agricultural land. Agricultural land in the Czech Republic has the structure of large fields and therefore the landscape structure appears to be suitable for using MERIS data with $300 \mathrm{~m}$ spatial resolution. Crop classification from MERIS in the Czech Republic has been already carried out by Brodsky et al. (2008). Our study has built on these results and evaluated the spectral characteristics of vegetation in detail. The presented results are helpful both in understanding the spectral characteristics of vegetation, as well as in the classification of land cover. These outcomes can be added to the existing vegetation spectral libraries.

\section{Acknowledgements}

The authors wish to thank the project GA13-16084S: "Social and economic driving forces of agricultural land losses in Czechia since 1990 from a regional perspective."

\section{References}

Aurdal, LRBH, Vikhamar, D \& Solberg, A 2005, Use of hidden Markov models and phenology for multitemporal satellite image classification: applications to mountain vegetation classification. Available from: <http://citeseerx.ist.psu.edu> [12 April 2012].

Bacour, C, Baret, V, Beal, D, Weiss, M \& Pavageau, K 2006, 'Neural network estimation of LAI, fAPAR, fCover and LAIxCab, from top of canopy MERIS reflectance data: Principles and validation'. Remote Sensing of Environment, vol. 105 , no. 4 , pp. 313-325.

Brodsky, L, Vobora, V, Sourkova, L \& Kodesova, R 2008, 'Supervised crop classification from midle-resolution multitemporal images', Proc. of the 2nd MERIS/(A)ATSR User Workshop, Frascati, Italy, 22-26 September 2008, pp. 34- 49 .
Dash, J, Mathur, A, Foody, GM, Curran, PJ, Chipman, J \& Lillesand, TM 2005, 'Land cover classification using multitemporal MERIS vegetation indices', International Journal of Remote Sensing, vol. 28, no. 6, pp.1137-1159.

European Space Agency 2009, EOLI (Earth Observation Link). Available from: <http://earth.esa.int/EOLi/EOLi.html> [20 April 2013].

European Space Agency 2010, BEAM Earth Observation Toolbox and Development Platform. Available from: <http://www.brockmann-consult.de/cms/web/beam/>. [25 June 2013].

European Space Agency 2010, GlobCorine. Available from: <http://due.esrin.esa.int/prjs/prjs114.php>. [14 June 2010].

European Space Agency 2010, GlobCover. Available from: <http://ionia1.esrin.esa.int/>. [14 June 2010]. 
Goddard Earth Sciences Data and Information Services Center 2013, Giovanni - Interactive Visualization and Analysis. Available from: <http://disc.sci.gsfc.nasa.gov/giovanni>. [5 July 2012].

Guanter, L, Gonzalez-Sanpedro, M \& Moreno, J 2007, 'A method for atmospheric correction of ENVISAT/MERIS data over land targets', International Journal of Remote sensing, vol. 28, no. 3-4, pp. 709-728.

Junxiang, L, Liangjun, D, Yujie, W \& Yongchang, S 2006, 'Vegetation classification of East China with multi-temporal NOAA-AVHRR data', Front. Biol. China, vol. 1, no. 3, pp. 303-309.
LPIS Sitewell 2004. Available from: <http://www.lpis.cz>. [20 September 2013].

Zhang, XY, Friedl, MA, Schaaf, CB, Strahler, AH, Hodges, JCF, Gao, F, Reed, BC \& Huete, A 2003, 'Monitoring vegetation phenology using MODIS'. Remote Sensing of Environment, vol. 84 , no. 2, pp. 471-475.

Zurita-Milla, R 2008, 'Mapping and monitoring heterogenous landscapes: spatial, spectral and temporal unmixing of MERIS data', PhD Thesis, Wageningen University, p. 138. 